\title{
Measurement of health-related quality of life in patients with diabetes mellitus using EQ-5D-5L in Hong Kong, China
}

\author{
Eliza Lai yi Wong ${ }^{1} \cdot$ Richard Huan $\mathrm{Xu}^{1} \cdot$ Annie Wai ling Cheung ${ }^{1}$
}

Accepted: 21 February 2020 / Published online: 5 March 2020

(c) The Author(s) 2020

\begin{abstract}
Purpose This study aimed to estimate the health preference scores of the Chinese population with Diabetes Mellitus (DM) using the EQ-5D-5L Hong Kong (HK) population tariff according to different sociodemographic characteristics in HK.

Methods Data were obtained from a cross-sectional, territory-wide study of patient experience on specialist outpatient services in a public setting in HK. The EQ-5D-5L HK was used to collect the patients' health status. A total of 2326 respondents were reported to suffer from DM, and their information was elicited and used for the analysis in this study. A robust ANOVA method was used to compare the differences in EQ-5D-5L index scores among subgroups. Binary logistic regressions were used to predict the probability of respondents reporting full health, and ordinal least square (OLS) model was used to assess the relationship between DM and health-related quality of life (HRQoL).

Results The mean EQ-5D-5L index score for DM patients was 0.84. A total of 229 EQ-5D health states were reported. Altogether, $47.5 \%$ of the respondents reported having some problems with pain/discomfort, followed by mobility (26.4\%), usual activities (26.0\%), and anxiety/depression (23.5\%). Logistic regression and OLS models indicated that male and fully employed respondents were less likely to report having problems with any of the five dimensions and index score of EQ-5D than female and non-fully employed respondents. The findings of OLS model also showed that DM patients that experience comorbidity with three and more chronic conditions were more likely to show a lower index score than respondents who reported living with DM alone.

Conclusion The EQ-5D index scores varied among DM patient characteristics and were more highly impaired with multimorbidity status. Interventions targeting at-risk subgroups, such as modifying single-diseased guidelines, might be helpful to improve their HRQoL.
\end{abstract}

Keywords Health-related quality of life $\cdot$ Diabetes mellitus $\cdot$ EQ-5D index score $\cdot$ China

\section{Introduction}

Diabetes mellitus (DM) is a chronic condition that is due to a lack of insulin from the pancreas or an inadequate efficiency of insulin level leading to severe complications in

Eliza Lai yi Wong and Richard Huan Xu are contributed equally to this work.

Electronic supplementary material The online version of this article (https://doi.org/10.1007/s11136-020-02462-0) contains supplementary material, which is available to authorized users.

Richard Huan Xu

richardhxu@cuhk.edu.hk

1 Jockey Club School of Public Health and Primary Care, The Chinese University of Hong Kong, Hong Kong, China many parts of the body and significantly increasing the risk of disability and premature death [1]. In the long term, DM is prone to causing heart attack, stroke, kidney failure, leg amputation, vision loss, nerve damage, and even depression [1-5], resulting in negative associations with physical, mental, and social well-being on an individual as well as on health-related quality of life (HRQoL). In a World Health Organization report, DM ranks as the seventh leading cause of deaths globally, with an estimation of 1.6 million direct deaths per year [6]. In Hong Kong (HK), DM has been listed as one of the major causes of morbidity and mortality. In 2017, more than 14,000 inpatient discharges and deaths were related to DM, accounting for $0.6 \%$ of total [7].

Given the globally increasing prevalence of DM, strategies to assess the influence of this disease as well as the outcomes of clinical interventions and effectiveness of 
healthcare policies in different populations are necessary. Currently, clinical indicators are still considered to be the golden criteria for assessing the effectiveness of interventions. However, academic debates on this issue have been raised because clinical indicators are insufficient to capture the overall well-being of an individual with DM [8-10]. Recently, there has been increasing attention on patients' self-reported health outcomes. Generic preference-based measures (GPBMs) are being utilised to measure the HRQoL of DM patients [11]. Measuring HRQoL can capture the variations in health status of patients with different demographic backgrounds and socioeconomic characteristics at different stages of DM [12]. Quantifying these differences in the health status of DM patients is critical for enabling healthcare professionals to understand the relationship between DM and individuals' health and well-being. Additionally, GPBMs can provide information on different domains of health and/or well-being for resource allocation by conducting economic evaluation of healthcare polices or clinical interventions and then facilitating decision-making $[13,14]$.

Currently, the EuroQol five-dimension questionnaire (EQ-5D) is one of the most extensively used GPBMs in measuring health status around the world [15]. This measure can derive an index score based on the local value set to estimate quality-adjusted life years and facilitate a cost-utility analysis [11]. EQ-5D is the preferred measure of HRQoL for health technology assessment in many European countries $[16,17]$. Limited cross-sectional studies using GPBMs to explore the relationship between DM and HRQoL among Chinese population have been conducted in HK. Luk and colleagues, using a UK tariff, reported that female, older, and obese DM respondents were more likely to report a lower EQ-5D index score [18]. Wan and colleagues, using SF-6D, found that being female, unmarried, current smoker, and obese were predictors of poor HRQoL among people with DM [19]. Xu and colleagues, using an EQ-5D HK population tariff, indicated that the patients with multimorbidity tend to report a low HRQoL; however, the profile of DM was not specifically reported [20]. Since preference-based HRQoL is strongly influenced by cultural contexts and the local health system design, it is important to study and report the relationship between DM and individuals' HRQoL using the validated HK EQ-5D tariff. Thus, this study aimed to estimate health preference-based index scores of the Hong Kong Chinese population with DM using the EQ-5D-5L HK population tariff. Such findings could provide an overall summary of HRQoL of individuals with DM, which is a useful reference for the economic evaluation of DM management and an important milestone in the development of patient-centred care.

\section{Method}

\section{Data collection}

Secondary data from a territory-wide cross-sectional patient experience survey among the attendees at specialist outpatient clinics (SOPCs) in HK were collected [21]. Respondents were recruited from all 26 public SOPCs across all 18 districts in HK. The targets were those who used specialist outpatient services during the survey period, aged $\geq 18$ years, and able to understand and speak Cantonese. Attendees at paediatric, hospice, psychiatric, dental, anaesthesiology, pathology, or nurse-led or multispecialty outpatient clinics were excluded from the study. Experienced interviewers conducted the telephone survey within 2 weeks after attendance. A structured questionnaire was used in the survey to indicate the attendees' experience using the HA services. In addition, the sociodemographic characteristics and health status of the respondents were collected regarding self-reported chronic conditions and through the questions of EQ-5D.

\section{Health preference score using EQ-5D-5L}

The EQ-5D-5L HK Chinese version was employed to report the health status and evaluate the health preference score of the respondents. The EQ-5D-5L HK was developed and validated in HK cultural settings based on the international protocol provided by the EuroQol Group, which allowed the evaluation of people's HRQoL by considering their perceptions of the HK context of culture and value systems [22]. EQ-5D-5L has five dimensions: mobility (MO), selfcare (SC), usual activities (UA), pain/discomfort (PD), and anxiety/depression (AD). Each dimension has five levels: no, slight, moderate, severe problems, and extreme/unable to. All health states defined by EQ-5D-5L can be converted into a single health preference index to provide a summary of HRQoL using the HK population tariff [22].

\section{Statistical analysis}

Descriptive statistics were used to summarise respondent characteristics. The health preference score was reported as means and standard deviations (SD). The demographic and socioeconomic characteristic information were recorded for analysis. Age and educational attainment were categorised into three separate groups; living (live alone, live with family/others, live in the institution) and employment status (retired, unemployed, and employed) were used as proxy questions to reflect the respondents' socioeconomic situation. Multimorbidity with DM was categorised into four groups [1 (only DM), 2 (DM with 1 more chronic disease), 
3 (DM with 2 more chronic diseases), and $\geq 4$ (DM with 3 or more chronic diseases)]. A chi-squared test was used to compare the differences in the reporting problems on each dimension of EQ-5D-5L across different subgroups. Given that the EQ-5D-5L index score was non-normally distributed (Shapiro-Wilk test, $p<0.05$ ), the differences in EQ5D-5L index scores among subgroups were assessed using the bootstrap version $(n=599)$ of a robust ANOVA method [23]. Binary multivariable logistic regressions were used to predict the probability of respondents reporting full health ( 0 and 1 , where 0 indicates no problem and 1 indicates any problem reported) on each of the five dimensions of EQ-5D-5L. Ordinal least squares (OLS) model was used to explore the relationship between DM and EQ-5D index score. Pairwise deletion was performed to resolve missing values. The data were analysed using $\mathrm{R}$ ( $\mathrm{R}$ foundation, Austria) and STATA (StataCorp LP, TX, USA), and statistical significance was set as $p$ value $\leq 0.05$.

\section{Results}

A total of 13,966 respondents completed the survey, of which 2326 who suffered from DM were extracted for secondary data analysis. The demographics of the extracted study population is shown in Table 1 . Nearly half of the respondents were female (50\%) and retired (56.3\%). The majority of them were aged $\geq 65$ years (60\%), only had a primary educational level or below (52\%), were living with families $(93 \%)$, and self-reported more than one chronic disease $(70 \%)$.

Overall, the mean health preference-based index score using EQ-5D-5L in respondents with DM was 0.84 out of 1 with a range between -0.86 and 1.0. Table 2 presents the estimated health preference-based score of respondents with DM by demographics, socioeconomic status, and level of multimorbidity. Among respondents with DM, 42.9\% reported full health (index score $=1.0$ ). Men seemed to have better health conditions than women; $52.3 \%$ of men reported full health vs. only $33.8 \%$ of women. Both male and female respondents had higher health preference-based index scores if they were young, were highly educated, lived with their families, were fully employed, and suffered from few chronic conditions. Figure 1 depicts the distribution of EQ-5D-5L index scores; the scores were highly skewed ( $>40 \%$ reported full health).

Table 3 presents the most frequently reported health states among all the 229 health states and the corresponding index score for participants with DM. The full health state was ' 11,111 ', and nearly $15 \%$ of the respondents $(n=339)$ reported a health state of ' 11,121 ' (index score $=0.924$ ), which indicates that the respondents reported no problems on MO, SC, UA, and AD, but had slight problems on PD.
Table 1 Characteristics of the respondents reported with DM $(n=2326)$

\begin{tabular}{|c|c|c|}
\hline & \multicolumn{2}{|c|}{ Overall } \\
\hline & $n$ & $\%$ \\
\hline \multicolumn{3}{|l|}{ Sex } \\
\hline Male & 1143 & 49.1 \\
\hline Female & 1183 & 50.9 \\
\hline \multicolumn{3}{|l|}{ Age group (mean $[\mathrm{sd}]$ ) } \\
\hline $18-44$ & 73 & 3.1 \\
\hline $45-64$ & 876 & 37.7 \\
\hline$\geq 65$ & 1377 & 59.2 \\
\hline \multicolumn{3}{|l|}{ Education } \\
\hline No/Primary & 1208 & 52.0 \\
\hline Secondary/Post-secondary & 912 & 39.2 \\
\hline Tertiary or above & 204 & 8.8 \\
\hline \multicolumn{3}{|l|}{ Current living status } \\
\hline Live alone & 148 & 6.4 \\
\hline Live with family/others & 2161 & 93.1 \\
\hline Live in institution ${ }^{\mathrm{a}}$ & 12 & 0.5 \\
\hline \multicolumn{3}{|l|}{ Current work status } \\
\hline Retired & 1307 & 56.3 \\
\hline Unemployed $^{\mathrm{b}}$ & 444 & 19.1 \\
\hline Employed $^{\mathrm{c}}$ & 572 & 24.6 \\
\hline \multicolumn{3}{|l|}{ Multimorbidity } \\
\hline DM only [1] & 725 & 31.2 \\
\hline DM with 1 more CD [2] & 1071 & 46.0 \\
\hline DM with 2 more CD [3] & 508 & 21.8 \\
\hline DM with 3 / more $C D[\geq 4]$ & 22 & 0.9 \\
\hline
\end{tabular}

$C D$ chronic disease(s)

${ }^{a}$ Include Convalescent Hospital/Rehabilitation Hospital/Hospital, and old age home

${ }^{\mathrm{b}}$ Unemployment included unemployed, home-maker and full-time student

${ }^{\mathrm{c}}$ Employment included full-time worker and part-time worker

Among the top 32 health states, the lowest index score was '22,332' $(n=11$, index score $=0.482)$, signifying a slight problem on $\mathrm{MO}, \mathrm{SC}$, and $\mathrm{AD}$ and a moderate problem on UA and PD. The health states reported by female respondents were similar to those in the overall pattern; however, for male participants, the order of health states was slightly different. Distributions according to sex are reported in the Online Appendix.

Table 4 demonstrates the proportion of the respondents reporting having 'any problem' on each dimension of EQ-5D-5L. The percentages of having any problem on the dimensions $\mathrm{PD}, \mathrm{MO}, \mathrm{UA}, \mathrm{AD}$, and $\mathrm{SC}$ were $47.5 \%, 26.4 \%$, $26.0 \%, 23.5 \%$, and $14.1 \%$, respectively. The proportion of reporting 'any problems' was higher in the subgroups of women, those with low educational levels and living in the institute, and those who were retired or with multimorbidity 
Table 2 The EQ-5D index score of the respondents reported without and with DM (stratified by sex)

Fig. 1 The distribution of EQ-5D index scores for overall, and stratified by male and female

\begin{tabular}{|c|c|c|c|c|c|c|}
\hline & \multicolumn{2}{|l|}{ Overall } & \multicolumn{2}{|l|}{ Male } & \multicolumn{2}{|l|}{ Female } \\
\hline & Mean (SD) & $p$ value & Mean (SD) & $p$ value & Mean (SD) & $p$ value \\
\hline \multicolumn{7}{|l|}{ Overall } \\
\hline EQ-5D index score & $0.84(0.23)$ & & $0.88(0.2)$ & & $0.81(0.24)$ & $<0.01$ \\
\hline EQ-5D index score $=1, \%$ & 42.9 & & 52.3 & & 33.8 & \\
\hline Range of index score & -0.86 to 1.0 & & -0.76 to 1.0 & & -0.86 to 1.0 & \\
\hline \multicolumn{7}{|l|}{ Age group } \\
\hline $18-44$ & $0.95(0.1)$ & $<0.001$ & $0.93(0.12)$ & $<0.001$ & $0.96(0.08)$ & $<0.001$ \\
\hline $45-64$ & $0.89(0.17)$ & & $0.92(0.15)$ & & $0.87(0.17)$ & \\
\hline$\geq 65$ & $0.80(0.26)$ & & $0.85(0.23)$ & & $0.76(0.27)$ & \\
\hline \multicolumn{7}{|l|}{ Education } \\
\hline No/Primary & $0.8(0.25)$ & $<0.001$ & $0.85(0.22)$ & 0.001 & $0.77(0.27)$ & $<0.001$ \\
\hline Secondary/ Post-secondary & $0.88(0.19)$ & & $0.90(0.2)$ & & $0.86(0.18)$ & \\
\hline Tertiary or above & $0.89(0.13)$ & & $0.90(0.15)$ & & $0.87(0.15)$ & \\
\hline \multicolumn{7}{|l|}{ Current living status } \\
\hline Live alone & $0.79(0.23)$ & 0.014 & $0.86(0.21)$ & 0.105 & $0.75(0.24)$ & 0.359 \\
\hline Live with family/others & $0.85(0.22)$ & & $0.88(0.2)$ & & $0.82(0.23)$ & \\
\hline Live in institution ${ }^{a}$ & $0.45(0.57)$ & & $0.61(0.23)$ & & $0.33(0.72)$ & \\
\hline \multicolumn{7}{|l|}{ Current work status } \\
\hline Retired & $0.8(0.26)$ & $<0.001$ & $0.84(0.23)$ & 0.001 & $0.74(0.29)$ & $<0.001$ \\
\hline Unemployed $^{\mathrm{b}}$ & $0.85(0.19)$ & & $0.81(0.24)$ & & $0.86(0.18)$ & \\
\hline Employed $^{\mathrm{c}}$ & $0.94(0.11)$ & & $0.94(0.11)$ & & $0.92(0.1)$ & \\
\hline \multicolumn{7}{|l|}{ Multimorbidity } \\
\hline 1 & $0.88(0.19)$ & $<0.001$ & $0.91(0.18)$ & $<0.001$ & $0.86(0.2)$ & $<0.001$ \\
\hline 2 & $0.83(0.24)$ & & $0.88(0.19)$ & & $0.79(0.27)$ & \\
\hline 3 & $0.81(0.24)$ & & $0.84(0.24)$ & & $0.78(0.24)$ & \\
\hline$\geq 4$ & $0.69(0.3)$ & & $0.68(0.36)$ & & $0.71(0.2)$ & \\
\hline
\end{tabular}

$E Q-5 D$ EuroQol five-dimension five levels, $S D$ standard deviation

\#The comparison of index score between male and female

${ }^{a}$ Include Convalescent Hospital/Rehabilitation Hospital/Hospital, and old age home

${ }^{\mathrm{b}}$ Unemployment included unemployed, home-maker and full-time student

${ }^{\mathrm{c}}$ Employment included full-time worker and part-time worker
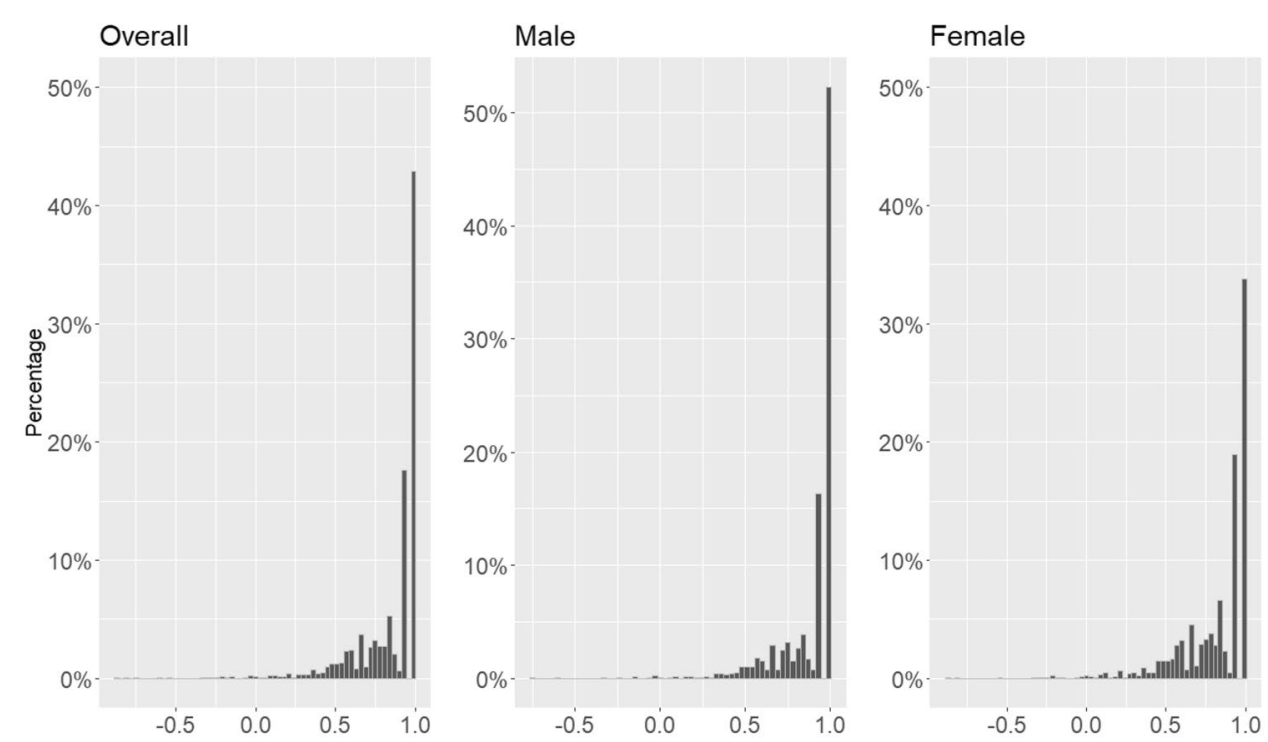
Table 3 The most frequent reported health states of EQ-5D among the respondents

\begin{tabular}{|c|c|c|c|c|c|}
\hline & State & $n$ & $\%$ & $\% \%{ }^{\mathrm{d}}$ & Index score \\
\hline 1 & $11,111^{\mathrm{a}}$ & 997 & 42.86 & 42.86 & 1.0 \\
\hline 2 & 11,121 & 339 & 14.57 & 57.43 & 0.924 \\
\hline 3 & 11,122 & 73 & 3.14 & 60.57 & 0.844 \\
\hline 4 & 11,112 & 57 & 2.45 & 63.02 & 0.919 \\
\hline 5 & 11,131 & 44 & 1.89 & 64.91 & 0.852 \\
\hline 6 & 21,221 & 41 & 1.76 & 66.67 & 0.747 \\
\hline 7 & 11,221 & 33 & 1.42 & 68.09 & 0.857 \\
\hline 8 & 21,222 & 33 & 1.42 & 69.51 & 0.667 \\
\hline 9 & 22,222 & 31 & 1.33 & 70.84 & 0.581 \\
\hline 10 & 11,132 & 29 & 1.25 & 72.09 & 0.772 \\
\hline 11 & 11,133 & 25 & 1.07 & 73.16 & 0.712 \\
\hline 12 & 21,211 & 25 & 1.07 & 74.23 & 0.823 \\
\hline 13 & 21,121 & 23 & 0.99 & 75.22 & 0.815 \\
\hline 14 & 11,222 & 20 & 0.86 & 76.08 & 0.777 \\
\hline 15 & 22,211 & 19 & 0.82 & 76.90 & 0.736 \\
\hline 16 & 22,221 & 19 & 0.82 & 77.72 & 0.661 \\
\hline 17 & 11,211 & 15 & 0.64 & 78.36 & 0.932 \\
\hline 18 & 22,322 & 15 & 0.64 & 79.00 & 0.554 \\
\hline 19 & 11,113 & 14 & 0.60 & 79.60 & 0.860 \\
\hline 20 & 22,231 & 13 & 0.56 & 80.16 & 0.589 \\
\hline 21 & 21,111 & 12 & 0.52 & 80.68 & 0.890 \\
\hline 22 & 21,122 & 12 & 0.52 & 81.20 & 0.734 \\
\hline 23 & 21,231 & 12 & 0.52 & 81.72 & 0.676 \\
\hline 24 & 22,232 & 11 & 0.47 & 82.19 & 0.509 \\
\hline 25 & 22,332 & 11 & 0.47 & 82.66 & 0.482 \\
\hline 26 & 32,221 & 11 & 0.47 & 83.13 & 0.588 \\
\hline 27 & 21,232 & 9 & 0.39 & 83.52 & 0.596 \\
\hline 28 & 11,123 & 8 & 0.34 & 83.86 & 0.784 \\
\hline 29 & 31,311 & 8 & 0.34 & 84.20 & 0.723 \\
\hline 30 & 11,142 & 7 & 0.30 & 84.50 & 0.612 \\
\hline 31 & $22,233^{b}$ & 7 & 0.30 & 84.80 & 0.449 \\
\hline \multirow[t]{3}{*}{32} & 31,111 & 7 & 0.30 & 85.10 & 0.817 \\
\hline & $\vdots$ & $\vdots$ & $\vdots$ & $\vdots$ & $\vdots$ \\
\hline & $55,555^{\mathrm{c}}$ & 1 & 0.04 & 100.00 & -0.864 \\
\hline
\end{tabular}

${ }^{\mathrm{a}} 11111$ means the respondents choose no problem on all five dimensions of EQ-5D-5L descriptive system

${ }^{b} 22233$ means the respondents choose slight problem on mobility, self-care and usual activities; moderate problem on pain/discomfort and anxiety/depression on EQ-5D-5L descriptive system

${ }^{\mathrm{c}}$ Overall, 229 states were reported

$\mathrm{d} \% \%$ cumulative percentage

than that in the other subgroups across the five dimensions of the EQ-5D-5L.

The binary logistic regression models indicated that it is highly possible for female DM patients to report having health problems on all the dimensions of EQ-5D. Compared with the respondents living alone, living in the institute was a statistically significant determinant for reporting problems in the MO dimension. Age had an impact on all the dimensions except for AD dimension. Additionally, DM patients living with three and more chronic conditions tended to report having more problems [Odds ratio (OR) 7.52, 95\% CI 3.02-20.43) on AD as well as the SC dimension (OR 5.13, 95\% CI 1.81-13.51) than patients reported living with DM alone (Table 5).

Table 5 showed that the DM patients who were female $(-0.058)$, old $(-0.004)$ and living in the institute $(-0.227)$ were more likely to show worse HRQoL (low index score) than the other DM patients. Moreover, the fully employed status had a positive impact on HRQoL for DM patients (beta $=0.031,95 \%$ CI 0.003-0.06). After adjusting for socioeconomic and demographic factors, our model identified that the respondents living with DM and two additional chronic conditions were more likely to show a lower index score than the patients (beta $=-0.035,95 \% \mathrm{CI}-0.06-0.011$ ) living with DM alone. The relationship was even more negative when the DM patients reported living with more than two chronic conditions (beta $=-0.173,95 \% \mathrm{CI}-0.264$ to -0.081 ). We found no statistically significant effect of educational attainment in the regression model.

\section{Discussion}

This study is first of its kind to employ secondary data from a territory-wide population survey in HK with the locally validated EQ-5D-5L instrument to report the health preference-based index score for DM patients. The findings show that the mean of health preference-based index scores for individuals with DM was 0.84 , which is comparatively lower than the index score of 0.92 in the general population [24]. Among DM patients, women reported lower index scores than did men, and the difference still appeared to be statistically significant even after adjusting for socioeconomic factors. The most obvious enhancement in the EQ-5D-5L index score was observed among fully employed patients. Age seems to have a relationship with decreasing HRQoL among all the DM patients. However, no statistically significant difference was identified in the EQ-5D-5L index scores among respondents with different educational levels, which was slightly different from findings from a previous study $[25,26]$. A Spanish study reported that patients reporting having DM had a mean EQ-5D-5L index score of 0.742 , and women scored lower than men [27]. McClure and colleagues reported that the mean index score was 0.790 for DM patients in Canada [28]. However, a recent study conducted in Finland shows that the mean EQ-5D-5L index score was 0.85 among the respondents with DM [29], which is similar to our results. When comparing our findings with those from other Asian countries, the mean index score in HK is a bit lower than in Korea, 0.87 [30], Japan, 0.86 [31], Singapore, 0.85 [32], and 0.87 in East China [33]. 
Table 4 Proportion of the respondents reported any problems on the five dimensions of EQ-5D-5L

\begin{tabular}{|c|c|c|c|c|c|c|c|c|c|c|}
\hline & \multicolumn{2}{|c|}{ Mobility } & \multicolumn{2}{|c|}{ Self-care } & \multicolumn{2}{|c|}{ Usual activities } & \multicolumn{2}{|c|}{ Pain/discomfort } & \multicolumn{2}{|c|}{$\begin{array}{l}\text { Anxiety/depres- } \\
\text { sion }\end{array}$} \\
\hline & $\%$ & $p$ value & $\%$ & $p$ value & $\%$ & $p$ value & $\%$ & $p$ value & $\%$ & $p$ value \\
\hline Overall & 26.4 & & 14.1 & & 26.0 & & 47.5 & & 23.5 & \\
\hline \multicolumn{11}{|l|}{ Sex } \\
\hline Male & 21.5 & $<0.001$ & 11.4 & $<0.001$ & 20.2 & $<0.001$ & 38.4 & $<0.001$ & 17.7 & $<0.001$ \\
\hline Female & 31.3 & & 16.7 & & 31.6 & & 56.2 & & 29.2 & \\
\hline \multicolumn{11}{|l|}{ Age group } \\
\hline $18-44$ & 4.1 & $<0.001$ & 1.4 & $<0.001$ & 5.5 & $<0.001$ & 28.8 & $<0.001$ & 16.4 & 0.11 \\
\hline $45-64$ & 14.2 & & 5.9 & & 14.4 & & 42.0 & & 22.0 & \\
\hline$\geq 65$ & 35.4 & & 20.0 & & 34.5 & & 51.9 & & 24.8 & \\
\hline \multicolumn{11}{|l|}{ Education } \\
\hline No/Primary & 34.8 & $<0.001$ & 20.0 & $<0.001$ & 34.7 & $<0.001$ & 53.9 & $<0.001$ & 26.5 & 0.002 \\
\hline Secondary/Post-secondary & 19.1 & & 7.7 & & 17.6 & & 40.8 & & 20.0 & \\
\hline Tertiary or above & 16.9 & & 7.8 & & 16.3 & & 39.7 & & 22.1 & \\
\hline \multicolumn{11}{|l|}{ Current living status } \\
\hline Live alone & 35.1 & $<0.001$ & 16.2 & $<0.001$ & 31.1 & $<0.001$ & 56.1 & $<0.001$ & 33.1 & 0.02 \\
\hline Live with family/others & 25.3 & & 13.6 & & 25.3 & & 46.7 & & 22.9 & \\
\hline Live in institution & 91.7 & & 58.3 & & 75.0 & & 83.3 & & 16.7 & \\
\hline \multicolumn{11}{|l|}{ Current work status } \\
\hline Retired & 36.1 & $<0.001$ & 21.1 & $<0.001$ & 34.9 & $<0.001$ & 51.9 & $<0.001$ & 25.2 & $<0.001$ \\
\hline Unemployed & 23.6 & & 9.2 & & 24.5 & & 54.5 & & 27.9 & \\
\hline Employed & 6.5 & & 1.9 & & 7.0 & & 32.0 & & 16.3 & \\
\hline \multicolumn{11}{|l|}{ Multimorbidity } \\
\hline 1 & 21.3 & $<0.001$ & 20.7 & $<0.001$ & 22.5 & $<0.001$ & 27.5 & 0.001 & 27.1 & $<0.001$ \\
\hline 2 & 49.7 & & 46.6 & & 48.3 & & 47.4 & & 46.6 & \\
\hline 3 & 27.5 & & 30.5 & & 27.6 & & 23.8 & & 23.8 & \\
\hline$\geq 4$ & 1.5 & & 2.1 & & 1.7 & & 1.3 & & 2.6 & \\
\hline
\end{tabular}

$E Q-5 D$ EuroQol five-dimension five levels, $S D$ standard deviation, $M O$ mobility, $S C$ self-care, $U A$ usual activities, $P D$ pain/discomfort, $A D$ anxiety/depression

$\%$ Percentage of reported any problem on dimension

Our results show that DM patients with multimorbidity status had statistically significant lower EQ-5D-5L index scores than patients with DM alone. This is in line with the other studies [31-33]. A study conducted in China on DM patients reported that the mean EQ-5D-5L index score is 0.876 , which decreased to 0.834 when patients report having comorbidities [33]. A UK study also indicated that patients with multimorbidity diabetes have a lower quality of life than other people [34]. Another study in Singapore reported a decrease in mean EQ-5D-5L index scores of between 0.028 and 0.043 for DM patients who reported having at least two complications [35].

We observed that the reduction in the index scores is strongly associated with having problems in the pain dimension (PD) in DM patients. Among the 10 most frequently reported EQ-5D health states from the respondents, eight included different levels of health problems in the PD dimension. These findings were in line with previous studies in other regions. A study conducted in Thailand reports that, compared to other dimensions of the EQ-5D, more than $50 \%$ of DM patients have reported problem with PD [26]. Another study in Singapore shows that 43\%, 41\%, and $48 \%$ of English, Chinese, and Malay speaking DM patients reported problems on PD, respectively [13]. Kapur identified that pain, particularly chronic pain, affects people with DM and interferes with their daily activities [36]. Geelen and colleagues indicated that pain intensity was associated with diminished quality of life [37].

In addition, although there is robust evidence that individuals experience symptoms of anxiety when they are diagnosed with diabetes [38, 39], in our study, DM patients with comorbidities with three or more chronic conditions were seven times more likely to report having problems with anxiety or depression, which was much higher than the findings of a previous study in HK [18]. One study supported the findings that the effect of depression on quality of life is 


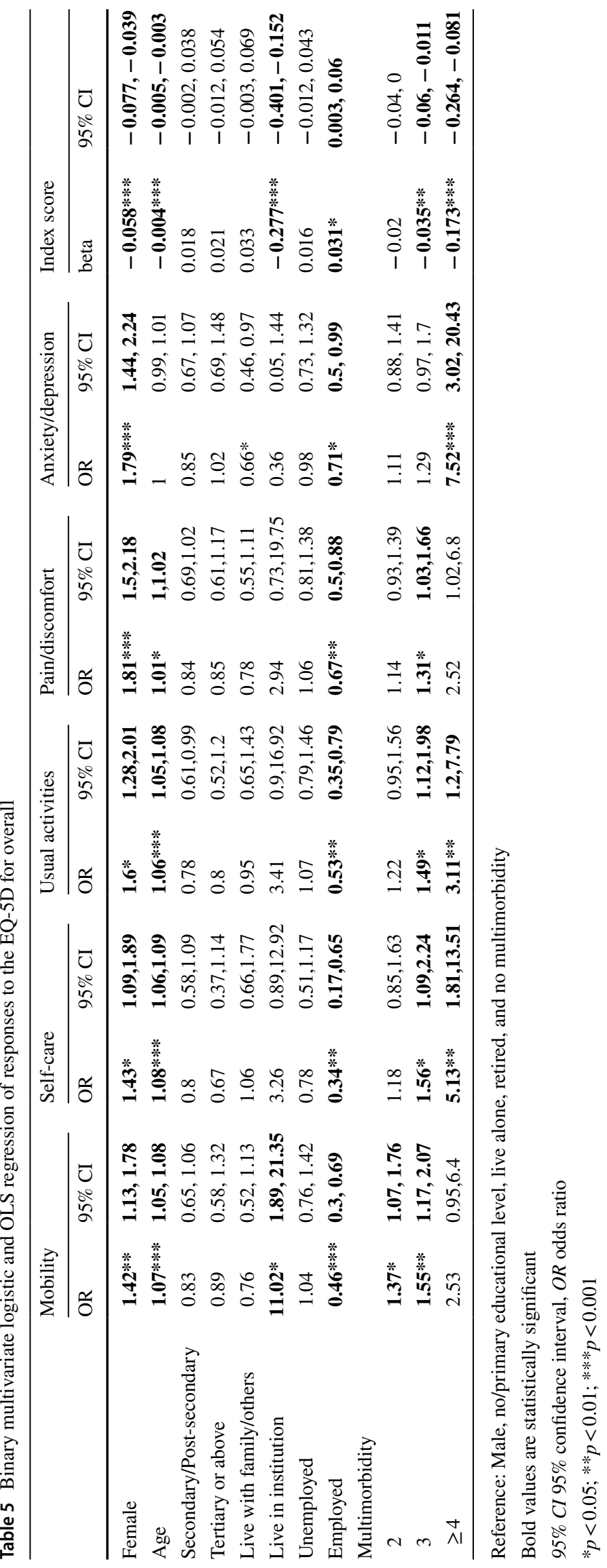


greater than the effect of diabetes on quality of life [39]. Several studies also addressed the idea that DM could increase the probability of suffering anxiety for DM patients in both local and international settings [37, 40]. The effect of multimorbidity on depression among DM patients did not accumulate, wherein the severity of depression might increase with an increased number of comorbidities. Furthermore, although there is a mixed picture of whether EQ-5D is able to reflect some variations of mental problems [41], our study provides some information that EQ-5D seems sensitive to detect the anxiety/depression in the DM Chinese population. Further tests are needed in the field of mental health.

This study provides a reference of health preference scores of the Chinese population with DM using the EQ5D-5L HK population tariff with different sociodemographic characteristics. The results are important for providing information for future cost-utility analyses of new drugs or policies targeting improving the health outcomes of DM treatments and facilitating the DM service planning at regional, national, and international levels. Moreover, to overcome the ceiling effect and some other characteristics of the EQ-5D data, different regression models (see Online Appendix) were run to ensure the validity and robustness of the estimation in the exploration of the relationship between DM and the HRQoL. The OLS model was proven to perform better than the other methods; however, further studies using other methods to test different populations are needed.

There are several limitations in this study. First, the information about health conditions was based on respondents' self-reports and we were not able to differentiate the type of $\mathrm{DM}$ and comprehensiveness of chronic conditions, which may hinder the subgroup analysis of relationship between DM and HRQoL. Second. The results of HRQoL were only based on the respondents from SOPCs in the public healthcare setting, and there is a lack of respondents with mild stages of DM or those from private settings, which may lead to potential selection bias.

\section{Conclusions}

The relationship between DM and patients' HRQoL in HK, China, was estimated using the EQ-5D-5L HK. To strive for the development of patient-centred care, the disease group information may provide insight into disease-based variations on HRQoL from a general population approach. Thus, it is important to adopt both generic and diseasespecific tools for patient-reported outcomes. We showed that the health preference-based index score varied among DM patient characteristics and were impaired with multimorbidity status. These findings provide a good base for an evaluation of DM service programmes, and future studies are required to determine whether these estimates are consistent in patients with different types of DM or from other clinical settings.

\section{Compliance with ethical standards}

Conflict of interest The authors declare that they have no conflict of interest.

Ethical approval Ethical approval of original study was obtained from the Chinese University of HK and the New Territory East Cluster Clinical Research Ethics Committee.

Informed consent Informed consent was obtained from all individual participants included in the study.

Open Access This article is licensed under a Creative Commons Attribution 4.0 International License, which permits use, sharing, adaptation, distribution and reproduction in any medium or format, as long as you give appropriate credit to the original author(s) and the source, provide a link to the Creative Commons licence, and indicate if changes were made. The images or other third party material in this article are included in the article's Creative Commons licence, unless indicated otherwise in a credit line to the material. If material is not included in the article's Creative Commons licence and your intended use is not permitted by statutory regulation or exceeds the permitted use, you will need to obtain permission directly from the copyright holder. To view a copy of this licence, visit http://creativecommons.org/licenses/by/4.0/.

\section{References}

1. Solli, O., Stavem, K., \& Kristiansen, I. (2010). Health-related quality of life in diabetes: The associations of complications with EQ-5D scores. Health and Quality of Life Outcomes, 8, 18. https ://doi.org/10.1186/1477-7525-8-18.

2. Basaraba, R., Ackart, D., Lakey, N., et al. (2015). Hyperglycemia and impaired glucose tolerance exacerbates tuberculosis and diabetes disease severity. Diabetes, 64, A707-A707.

3. Nambam, B., Haller, M., Schatz, D., et al. (2015). Is pancreas volume a marker of type 1 diabetes disease progression? A preliminary report. Diabetes, 64, A367-A367.

4. Jin, B., Liu, R., Hao, S., et al. (2017). Defining and characterizing the critical transition state prior to the type 2 diabetes disease. PLOS ONE, 12, e0180937. https://doi.org/10.1371/journ al.pone.0180937.

5. Pagano, G., Polychronis, S., Wilson, H., et al. (2018). Diabetes mellitus and Parkinson disease. Neurology, 90, e1654-e1662. https://doi.org/10.1212/WNL.0000000000005475.

6. World Health Organization. WHO Diabetes. (2018). https://www. who.int/en/news-room/fact-sheets/detail/diabetes.

7. Centre for Health Protection. Diabetes Mellitus. (2017). https:// www.healthyhk.gov.hk/phisweb/en/healthy_facts/disease_burde n/major_causes_death/diabetes_mellitus/.

8. Murillo, M., Bel, J., Pérez, J., et al. (2017). Impact of monitoring health-related quality of life in clinical practice in children with type 1 diabetes mellitus. Quality of Life Research, 26, 3267. https ://doi.org/10.1007/s11136-017-1682-6.

9. Weatherall, J., Polonsky, W. H., Lanar, S., et al. (2018). When insulin degludec enhances quality of life in patients with type 2 diabetes: A qualitative investigation. Health and Quality of Life Outcomes, 16, 87. https://doi.org/10.1186/s12955-018-0883-1. 
10. Tang, T. S., Yusuf, F. L. A., Polonsky, W. H., et al. (2017). Assessing quality of life in diabetes: II - Deconstructing measures into a simple framework. Diabetes Research and Clinical Practice, 126, 286-302. https://doi.org/10.1016/j.diabres.2016.10.007.

11. Sullivan, P. W., \& Ghushchyan, V. H. (2016). EQ-5D scores for diabetes-related comorbidities. Value in Health, 19, 1002-1008. https://doi.org/10.1016/j.jval.2016.05.018.

12. Janssen, M., Lubetkin, E. I., Sekhobo, J. P., et al. (2011). The use of the EQ-5D preference-based health status measure in adults with Type 2 diabetes mellitus. Diabetic Medicine, 28, 395-413. https://doi.org/10.1111/j.1464-5491.2010.03136.x.

13. Wang, Y., Tan, N.-C., Tay, E.-G., et al. (2015). Cross-cultural measurement equivalence of the 5-level EQ-5D (EQ-5D-5L) in patients with type 2 diabetes mellitus in Singapore. Health and Quality of Life Outcomes, 13, 103. https://doi.org/10.1186/s1295 5-015-0297-2.

14. Redekop, W. K., Koopmanschap, M. A., Stolk, R. P., et al. (2002). Health-related quality of life and treatment satisfaction in Dutch patients with type 2 diabetes. Diabetes Care, 25, 458. https://doi. org/10.2337/diacare.25.3.458.

15. Herdman, M., Gudex, C., Lloyd, A., et al. (2011). Development and preliminary testing of the new five-level version of EQ-5D (EQ-5D-5L). Quality of Life Research, 20, 1727-1736. https://doi. org/10.1007/s11136-011-9903-x.

16. Rencz, F., Gulácsi, L., Drummond, M., et al. (2016). EQ-5D in Central and Eastern Europe: 2000-2015. Quality of Life Research, 25, 2693-2710. https://doi.org/10.1007/s11136-016-1375-6.

17. Rowen, D., Azzabi Zouraq, I., Chevrou-Severac, H., et al. (2017). International regulations and recommendations for utility data for health technology assessment. Pharmacoeconomics, 35, 11-19. https://doi.org/10.1007/s40273-017-0544-y.

18. Luk, A., Li, X., Ozaki, R., et al. (2014). Comorbidities, healthrelated quality of life, and glycemic control in chinese patients with type 2 diabetes: The Hong Kong Joint Asia Diabetes Evaluation (JADE) Program. Diabetes, 63, A208-A208.

19. Wan, E., Fung, C., Choi, E., et al. (2016). Main predictors in health-related quality of life in Chinese patients with type 2 diabetes mellitus. Quality of Life Research, 25, 2957-2965. https:// doi.org/10.1007/s11136-016-1324-4.

20. Wong, E., Xu, R., \& Cheung, A. (2019). Measuring the impact of chronic conditions and associated multimorbidity on healthrelated quality of life in the general population in Hong Kong SAR, China: A cross-sectional study. PLoS ONE, 14, e0224970. https://doi.org/10.1371/journal.pone.0224970.

21. Xu, R. H., \& Wong, E. L. Y. (2017). Involvement in shared decision-making for patients in public specialist outpatient clinics in Hong Kong. Patient Preference and Adherence, 11, 505-512.

22. Wong, E. L. Y., Ramos-Goñi, J. M., Cheung, A. W. L., et al. (2018). Assessing the use of a feedback module to model EQ5D-5L health states values in Hong Kong. Patient, 11, 235-247. https://doi.org/10.1007/s40271-017-0278-0.

23. Wilcox, R. R. (2011). Introduction to robust estimation and hypothesis testing (3rd ed.). Amsterdam: Elsevier.

24. Wong, E. L. Y., Cheung, A. W. L., Wong, A. Y. K., et al. (2019). Normative profile of health-related quality of life for Hong Kong general population using preference-based instrument EQ5D-5L. Value in Health, 22, 916-924. https://doi.org/10.1016/j. jval.2019.02.014.

25. Arifin, B., Idrus, L., Asselt, A., et al. (2019). Health-related quality of life in Indonesian type 2 diabetes mellitus outpatients measured with the Bahasa version of EQ-5D. Quality of Life Research, 28, 1179-1190. https://doi.org/10.1007/s11136-019-02105-z.

26. Pattanaphesaj, J., \& Thavorncharoensap, M. (2015). Measurement properties of the EQ-5D-5L compared to EQ-5D-3L in the Thai diabetes patients. Health and Quality of Life Outcomes, 13, 14. https://doi.org/10.1186/s12955-014-0203-3.
27. Collado Mateo, D., García Gordillo, M. A., Olivares, P. R., et al. (2015). Normative values of EQ-5D-5L for diabetes patients from Spain. Nutricion Hospitalaria, 32, 1595. https://doi.org/10.3305/ nh.2015.32.4.9605.

28. Mcclure, N. S., Al Sayah, F., Ohinmaa, A., et al. (2018). Minimally important difference of the EQ-5D-51 index score in adults with type 2 diabetes. Value in Health, 21, 1090-1097. https://doi. org/10.1016/j.jval.2018.02.007.

29. Jalkanen, K., Aarnio, E., Lavikainen, P., et al. (2019). Impact of type 2 diabetes treated with non-insulin medication and number of diabetes-coexisting diseases on EQ-5D-5 L index scores in the Finnish population. Health and Quality of Life Outcomes, 17, 117. https://doi.org/10.1186/s12955-019-1187-9.

30. Choi, Y. J., Lee, M. S., An, S. Y., et al. (2011). The relationship between diabetes mellitus and health-related quality of life in Korean adults: The Fourth Korea National Health and Nutrition Examination Survey (2007-2009). Diabetes \& Metabolism Journal, 35, 587-594. https://doi.org/10.4093/dmj.2011.35.6.587.

31. Sakamaki, H., Ikeda, S., Ikegami, N., et al. (2006). Measurement of HRQL using EQ-5D in patients with type 2 diabetes mellitus in Japan. Value in Health, 9, 47-53. https://doi.org/10.111 1/j.1524-4733.2006.00080.x.

32. Pan, C.-W., Sun, H.-P., Wang, X., et al. (2015). The EQ-5D-5L index score is more discriminative than the EQ-5D-3L index score in diabetes patients. Quality of Life Research, 24, 1767-1774. https://doi.org/10.1007/s11136-014-0902-6.

33. Pan, C., Sun, H., Zhou, H., et al. (2016). Valuing health-related quality of life in type 2 diabetes patients in China. Medical Decision Making, 36, 234-241. https://doi.org/10.1177/0272989X15 606903.

34. Mujica-Mota, R., Roberts, M., Abel, G., et al. (2015). Common patterns of morbidity and multi-morbidity and their impact on health-related quality of life: Evidence from a national survey. Quality of Life Research, 24, 909-918. https://doi.org/10.1007/ s11136-014-0820-7.

35. Wang, P., Luo, N., Tai, E. S., et al. (2016). The EQ-5D-5L is more discriminative than the EQ-5D-3L in patients with diabetes in Singapore. Value in Health Regional Issues, 9, 57-62. https:// doi.org/10.1016/j.vhri.2015.11.003.

36. Kapur, D. (2003). Neuropathic pain and diabetes. Diabetes/Metabolism Research and Reviews, 19, S9-15. https://doi.org/10.1002/ dmrr.359.

37. Geelen, C. C., Smeets, R. J. E. M., Schmitz, S., et al. (2017). Anxiety affects disability and quality of life in patients with painful diabetic neuropathy. European Journal of Pain, 21, 1632-1641. https://doi.org/10.1002/ejp.1067.

38. Egede, L. E., \& Ellis, C. (2010). Diabetes and depression: Global perspectives. Diabetes Research and Clinical Practice, 87, 302312. https://doi.org/10.1016/j.diabres.2010.01.024.

39. Goldney, R. D., Phillips, P. J., Fisher, L. J., et al. (2004). Diabetes, depression, and quality of life: A population study. Diabetes Care, 27, 1066. https://doi.org/10.2337/diacare.27.5.1066.

40. Lee, S., Chiu, A., Tsang, A., et al. (2006). Treatment-related stresses and anxiety-depressive symptoms among Chinese outpatients with type 2 diabetes mellitus in Hong Kong. Diabetes Research and Clinical Practice, 74, 282-288. https://doi. org/10.1016/j.diabres.2006.03.026.

41. Brazier, J. (2010). Is the EQ-5D fit for purpose in mental health? British Journal of Psychiatry, 197, 348. https://doi.org/10.1192/ bjp.bp.110.082453.

Publisher's Note Springer Nature remains neutral with regard to jurisdictional claims in published maps and institutional affiliations. 